\title{
Postoperative analgesia with epidural fentanyl
}

\author{
SUE A. LYTLE, DO \\ DOUGLAS M. GOLDSMITH, DO \\ TRACY L. NEUENDORF, DO \\ MARSHALL E. LOWRY, DO
}

A retrospective analysis of 133 patients who received continuous epidural fentanyl for postoperative analgesia is presented. Using a concentration of $5 \mu \mathrm{g} / \mathrm{mL}$ of fentanyl, patients received continuous epidural infusions for 24 to 72 hours postoperatively. The average rate of infusion was $60 \mu \mathrm{g} / \mathrm{h}$. A total of $59.3 \%$ of the patients received no additional narcotics; $\mathbf{2 6 . 3 \%}$ required supplemental narcotics during the first 24 hours only. Three percent had the infusion discontinued because it provided poor pain control. Side effects were less than, or comparable to, those of epidural morphine. Respiratory depression, defined as a respiratory rate of less than 8, or apnea did not occur. Urinary retention occurred in one patient. Pruritus occurred in $4 \%$ (6 patients). Nausea occurred in $25.5 \%$, a rate comparable to that which occurred with epidural morphine. No side effects occurred in $\mathbf{7 0 . 6 \%}$ of the patients reviewed. These data show that epidural fentanyl provides good to excellent pain relief with minimal side effects.

From the Department of Anesthesia, Youngstown Osteopathic Hospital, Youngstown, Ohio, where at the time this article was written, Dr Goldsmith was chairman; and Drs Lytle, Neuendorf, and Lowry, attending anesthesiologists; Drs Goldsmith and Lowry are clinical professors and Dr Neuendorf, clinical assistant professor of anesthesia, Ohio University College of Osteopathic Medicine, Athens, Ohio.

Reprint requests to Sue A. Lytle, DO, Department of Anesthesia, Youngstown Osteopathic Hospital, 1319 Florencedale Ave, Youngstown, OH 44505.
(Key words: Epidural analgesia, fentanyl, postoperative pain)

The control of postoperative pain with epidural narcotics has been widely studied..$^{1-5} \mathrm{Im}$ proved ventilation, as compared with parenteral narcotics, has also been documented..$^{5,6}$ Epidural morphine has been most often studied and seems almost ideal for postoperative analgesia. Its long duration of action and low incidence of side effects are its main advantages. However, respiratory depression or apnea, which can occur with epidural morphine, can be life-threatening and requires close monitoring of the patients. ${ }^{1}$

Epidural fentanyl provides a similar quality of postoperative analgesia, yet it seems to have a decreased incidence of respiratory depression. ${ }^{3,7}$ It has a short term of effect (3 to 4 hours after each bolus dose). However, continuous infusions of fentanyl solutions epidurally have been used to provide safe, longterm (more than 24 hours) postoperative analgesia in general surgical patients. ${ }^{4} \mathrm{~A}$ continuous infusion allows more precise titration of doses while maintaining adequate blood levels of the drug. The purpose of this study was to provide a retrospective analysis of the use of continuous epidural fentanyl in 133 postsurgical patients in a community hospital setting.

\section{Materials and methods}

After receiving the approval of the hospital's bioethics committee, we reviewed the charts of 133 patients who had received continuous infusion of 
Table 1

Types of Surgical Procedures Performed in Patients Who Received Continuous Epidural Infusion of Fentanyl for Postoperative Pain Relief $(\mathrm{N}=133)$

\begin{tabular}{|lcr|}
\hline $\begin{array}{c}\text { Type of } \\
\text { procedure }\end{array}$ & $\begin{array}{c}\text { No. of } \\
\text { patients }\end{array}$ & $\% *$ \\
\hline - Abdominal, total & 73 & 54.9 \\
Upper & 31 & 23.3 \\
Lower & 42 & 31.6 \\
- Gynecologic & 27 & 20.3 \\
Obstetric & 11 & 8.3 \\
- Orthopedic & 8 & 6.0 \\
Thoracic & 9 & 6.8 \\
Vascular & 5 & 3.8 \\
\hline *Percentage total exceeds 100 because of rounding. & \\
\hline
\end{tabular}

epidural fentanyl for postoperative analgesia between March 1987 and May 1988. The side effects associated with the epidural narcotics and any supplemental narcotics used were recorded for each patient and results were compiled. Patients were American Society of Anesthesiology (ASA) class II through IV. There were 91 women $(68.4 \%)$ and 42 men $(31.6 \%)$. A wide variety of surgical procedures were performed (Table 1). At surgery, a total of 117 patients received a general anesthetic while 16 patients received continuous epidural anesthesia. Ages ranged from 18 to 90 years (median, 57.4 years). This included 45 patients $(33.8 \%)$ older than 70 years of age.

The method of postoperative analgesia had been discussed with all patients at the time of the preoperative visit, and informed consent had been obtained in all cases. The type of anesthetic given for the surgery was not a determining factor in the decision regarding postoperative analgesia.

Epidural catheters were placed during the anesthetic period, either before or after the surgical procedure. The epidural catheter was inserted at the L2-3 or L3-4 interspace and threaded approximately 3 to $5 \mathrm{~cm}$ cephalad into the epidural space. All patients received an injection of a test dose of $2 \mathrm{~mL}$ of $1.5 \%$ lidocaine. A microfilter was placed at the end of the epidural catheter, and all additional medications were injected through the filter. Before transportation of the patient to the recovery room, $100 \mu \mathrm{g}$ of fentanyl was injected into the epidural catheter. On the patient's arrival in the recovery room, the continuous infusion of epidural fentanyl solution was started. An infusion pump was used to control the rate of infusion. The con- centration of the drip was $5 \mu \mathrm{g} / \mathrm{mL}$ of fentanyl, using $500 \mu \mathrm{g}$ of fentanyl in $90 \mathrm{~mL}$ of preservativefree $0.9 \%$ saline solution. The infusion was started at a rate of 8 to $13 \mathrm{~mL} / \mathrm{h}$ (average, $60 \mu \mathrm{g} / \mathrm{h}$ ) and titrated to control pain. Continuous monitoring of vital signs and side effects was carried out by the nursing staff, beginning in the recovery room. Respiration and pulse rates were recorded hourly, as were the incidences of nausea and vomiting, pruritus, and complaints of urinary retention. Any supplemental narcotics given to the patient were also recorded.

All patients remained under the service of the department of anesthesia while the drips were being infused. No sedatives or narcotics were administered without the department's approval. Most patients were monitored on the general surgical ward, but some patients were transferred to the intensive care unit and were monitored there, as dictated by the type of surgery they had undergone.

\section{Results}

The majority of the patients $(74 \%)$ had continuous epidural analgesia for 72 hours. The epidural doses of patients who had undergone cesarean section were discontinued after 18 to 24 hours. At this point, most obstetric patients were requesting showers, and their pain was well-controlled by oral pain medications.

No additional pain medications were administered to 79 patients $(59.4 \%)$. Only 35 patients $(26.3 \%)$ required supplemental pain medications during the first 24 hours. Epidural analgesia was discontinued in four patients due to inadequate pain control. All four of these patients continued to complain of inadequate pain relief despite parenteral administration of narcotics.

No side effects occurred in $70.6 \%$ of the patients. No patient had apnea. Floor nurses monitored ventilatory status by measuring respiratory rates. There were no documented respiratory rates of less than 10 per minute, the rate at which administration of naloxone would be required.

Thirty-four patients $(25.6 \%)$ experienced nausea. In nine of these patients, the complaint was transient and occurred only once during the first 24 hours after surgery. All nine patients had received a general anesthetic.

Six patients reported having pruritus. Three 
of these patients had undergone cesarean sections. After receiving $0.4 \mathrm{mg}$ of naloxone administered intravenously, they had no further itching. A 29-year-old woman had her epidural infusion discontinued 24 hours after a cholecystectomy when severe itching was unrelieved by diphenhydramine and naloxone. The itching dissipated after the epidural infusion was discontinued.

One patient, a 50-year-old woman, had urinary retention as well as symptoms of nausea, vomiting, and pruritus. The symptoms developed more than 24 hours after cholecystectomy. At the patient's request, we continued the epidural fentanyl infusion for a total of 24 hours because she was receiving excellent pain relief (Table 2).

\section{Discussion}

Fentanyl is a highly lipid-soluble narcotic. Its onset of action in the epidural space is more rapid than that of morphine. Fentanyl's lipid solubility accounts for its rapid uptake by the opiate receptors in the spinal cord; this uptake leaves only minimal amounts to be absorbed systemically. ${ }^{1,7}$ This rapid uptake also prevents the formation of residual cerebrospinal fluid concentrations of the drug that can migrate rostrad and cause delayed respiratory depression, an occurrence seen with epidural morphine. ${ }^{1,8}$ Onset of action of epidural fentanyl, $0.1 \mathrm{mg}$, is 4 to 10 minutes, with complete relief attained in 20 minutes. The duration of action is 5 to 6 hours. ${ }^{1}$ Continuous infusions of smaller doses allow long-term relief with more precise titration of drug dosages.

It is well documented that epidural narcotics can provide superior pain relief when compared with parenteral narcotics. ${ }^{1,2}$ Epidural morphine has been reported to provide excellent to complete postoperative analgesia in $37 \%$ to $46 \%$ of patients. ${ }^{9,10}$ In our study, no additional narcotics were required in $59.3 \%$ of the patients.

Side effects observed with epidural narcotics include nausea, vomiting, pruritus, urinary retention, and respiratory depression. ${ }^{8}$ Studies have shown that the incidence of these side effects when narcotics are used is similar, no matter what the method of administration. ${ }^{11}$
Table 2

Complications in Patients Receiving

Continuous Epidural Infusion of Fentanyl

for Postoperative Pain Relief $(\mathrm{N}=133)$

\begin{tabular}{|c|c|c|}
\hline Complication & $\begin{array}{c}\text { No. of } \\
\text { patients* } \\
(\mathbf{n}=39)\end{array}$ & $\%$ \\
\hline Nausea & 34 & 25.5 \\
\hline Pruritus & 6 & 4.5 \\
\hline Urinary retention & 1 & 0.7 \\
\hline Respiratory depression & 0 & 0 \\
\hline
\end{tabular}

* One patient had urinary retention in addition to nausea and pruritus

Our own data for epidural fentanyl indicated similar to fewer instances of side effects than those described for epidural morphine. In addition, our chart review showed no infections or hematomas from the use of the epidural catheter.

Because of its short serum half-life and lipid solubility, epidural fentanyl causes fewer instances of respiratory depression. The improvement in ventilatory status also seen with this drug may outweigh the risks of respiratory depression..$^{3,7,12}$ In 1987, Negre and associates ${ }^{7}$ showed a decrease in the ventilatory response to $\mathrm{CO}_{2}$ with epidural fentanyl. Renaud and colleagues ${ }^{3}$ showed a decreased minute ventilation and an increased end tidal $\mathrm{CO}_{2}$, but minute volume and end tidal $\mathrm{CO}_{2}$ were mild and nonsignificant when doses of epidural fentanyl of $1 \mu \mathrm{g} / \mathrm{kg} / \mathrm{h}$ were used. We believe that epidural fentanyl may be safer than epidural morphine when considering respiratory depression. Our own experience with epidural morphine has shown several instances of respiratory depression requiring administration of naloxone, including one episode of apnea. Despite the improved safety and effectiveness, we continue to closely monitor patients to whom we have administered postoperative epidural narcotics.

Nausea and vomiting are frequent postoperative occurrences. A $30 \%$ incidence of nausea and vomiting has been reported when intravenous or intramuscular opioids are used postsurgically. ${ }^{1,6}$ The reported incidence of nausea after epidural morphine ranged from $16 \%$ 
to $50 \% .^{1,9,13}$ In our study, the incidence of nausea with epidural fentanyl was $25 \%$.

Six $(4.5 \%)$ of the patients complained of pruritus during epidural fentanyl administration. In five of the patients, the itching was transient. An incidence of up to $90 \%$ has been reported with epidural morphine. ${ }^{14,15}$ No relationship between the dose of epidural narcotics and the incidence of pruritus has been determined. ${ }^{14}$ Severe pruritus appears to affect about $1 \%$ of patients. This incidence compares with that in our study: one patient had her epidural dose discontinued because of severe itching.

Because of the high incidence (up to $100 \%$ ) of urinary retention with epidural morphine, ${ }^{15-17}$ it had been the protocol at our institution for patients receiving epidural narcotics to have a Foley catheter inserted during surgery and maintained in place until the administration of epidural narcotics was discontinued. The low incidence $(0.7 \%)$ of urinary retention with epidural fentanyl has changed that practice. Foley catheters are inserted perioperatively only when needed to monitor urinary output or when the type of surgical procedure being performed indicates the need. The catheters are removed at the discretion of the surgeon (usually within 24 hours).

Our use of epidural fentanyl in elderly patients revealed no increased incidence of side effects when compared with epidural morphine. In patients of extreme age (older than 85 years), decreased doses of narcotics were used with excellent analgesia and minimal, if any, side effects.

\section{Conclusion}

The use of continuous epidural fentanyl provides postoperative pain relief with minimal side effects. The nursing staff and patients have expressed greater satisfaction with epidural fentanyl as compared with epidural morphine. Despite the low incidence of side effects, it is still important to monitor patients after receiving continuous infusion of epidural fentanyl. We believe administration of epidural fentanyl by continuous infusion can be done safely on a general surgical floor.

1. Cousins MJ, Mather LE: Intrathecal and epidural administration of opioids. Anesthesiology 1984;61:276-310.

2. Lomessy A, Magnin C, Viale J-P, et al: Clinical advantages of fentanyl given epidurally for postoperative analgesia. Anesthesiology 1984;61:466-469.

3. Renaud B, Brichant JF, Clerque F, et al: Continuous epidural fentanyl: Ventilatory effects and plasma kinetics. Anesthesiology 1985;63(3A):A234.

4. Bailey PW, Smith BE: Continuous epidural infusion of fentanyl for postoperative analgesia. Anaesthesia 1980;35:10021006.

5. Reiswig SD, Buckley RL: Control of postoperative pain: Comparison of the effects of epidural and narcotic analgesia. JAOA 1975;75:165-169.

6. Mackersie RC, Shackford SR, Hoyt DB, et al: Continuous epidural fentanyl analgesia: Ventilatory function improvement with routine use in treatment of blunt chest injury. Trauma 1987;27:1207-1212.

7. Negre I, Gueneron JP, Ecoffey C, et al: Ventilatory response to carbon dioxide after intramuscular and epidural fentanyl. Anesth Analg 1987;66:707-710.

8. Stoetling R: Pharmacology and Physiology in Anesthetic Practice. Philadelphia, JB Lippincott, 1987, pp 73.

9. Mehnert JH, Dupont TJ, Rose DD: Intermittent epidural morphine instillation for control of postoperative pain. Am J Surg 1983;146:145-151.

10. Cullen ML, Staren ED, El-Ganzouri A, et al: Continuous epidural infusion for analgesia after major abdominal operations: A randomized, prospective double-blind study. Surgery 1985;98:718-728

11. Miller R (ed): Anesthesia. New York, Churchill, Livingstone, 1986, pp 1104-1105.

12. Muir JJ, Warner MA, Offord KP, et al: Role of nitrous oxide and other factors in postoperative nausea and vomiting: A randomized and blinded prospective study. Anesthesiology 1987;66:513-518.

13. Reiz S, Westberg M: Side effects of epidural morphine, letter. Lancet 1980;2:203-204.

14. Martin R, Salbaing J, Blaise G, et al: Epidural morphine for postoperative pain relief: A dose-response curve. Anesthesiology 1982;56:423-326.

15. Staren ED, Cullen ML: Epidural catheter analgesia for the management of post-operative pain. Surg Gynecol Obstet 1986;162:389-403.

16. Bromage PR, Camporesi EM, Durant PAC, et al: Nonrespiratory side effects of epidural morphine. Anesth Analg 1982;61:490-495.

17. Rawal N, Sjöstrand U, Dahlström B: Postoperative pain relief by epidural morphine. Anesth Analg 1981;60:726-731. 
Treat

hypertension
at its source

with...

NEW, ONCE-A-DAY II

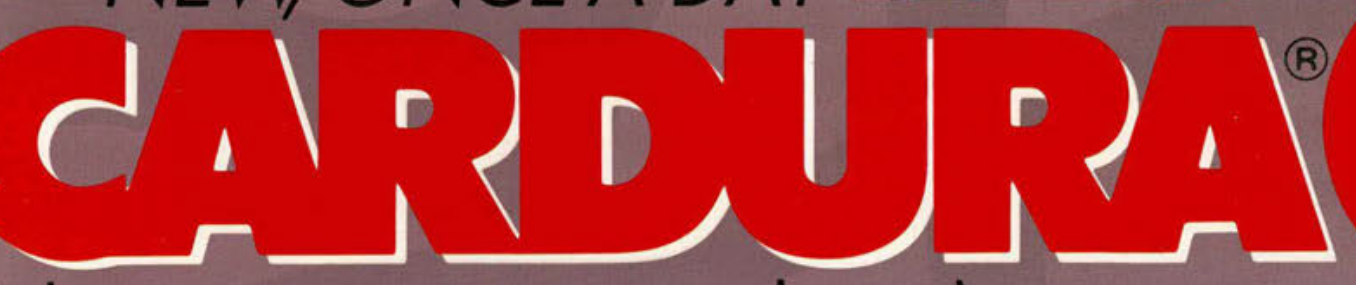

(doxazosin mesylate) $\begin{aligned} & \text { Scored Tablets } \\ & 1 \mathrm{mg}, 2 \mathrm{mg}, 4 \mathrm{mg}, 8 \mathrm{mg}\end{aligned}$ 


\section{Vasculoactive CARDURA}

$\therefore$ CARDURA is effective first-line therapy for hypertension

¿2 CARDURA lowers blood pressure regardless of age or race'

S? CARDURA provides smooth 24-hour efficacy with once-a-day dosing ${ }^{2}$

is CARDURA has shown excellent long-term blood pressure control ${ }^{3}$ Long-term effect of CARDURA on mean standing blood pressure ${ }^{3}$

Eighty patients treated with doxazosin in an extended, open-label treatment period following a l-year double-blind study; over the 3-year study period, $76.3 \%(61)$ were considered a therapeutic success on a mean daily dose of $4.8 \mathrm{mg}$. Therapeutic success: reduction in sitting diastolic blood pressure by $\geq 10 \mathrm{~mm} \mathrm{Hg}$, or to $\leq 90 \mathrm{~mm} \mathrm{Hg}$ with a fall of $\geq 5 \mathrm{~mm} \mathrm{Hg}$.

Data on blood pressure changes in 65 patients who completed 36 months of therapy are shown here. The mean daily dose for these 65 patients was $5.0 \mathrm{mg}$.

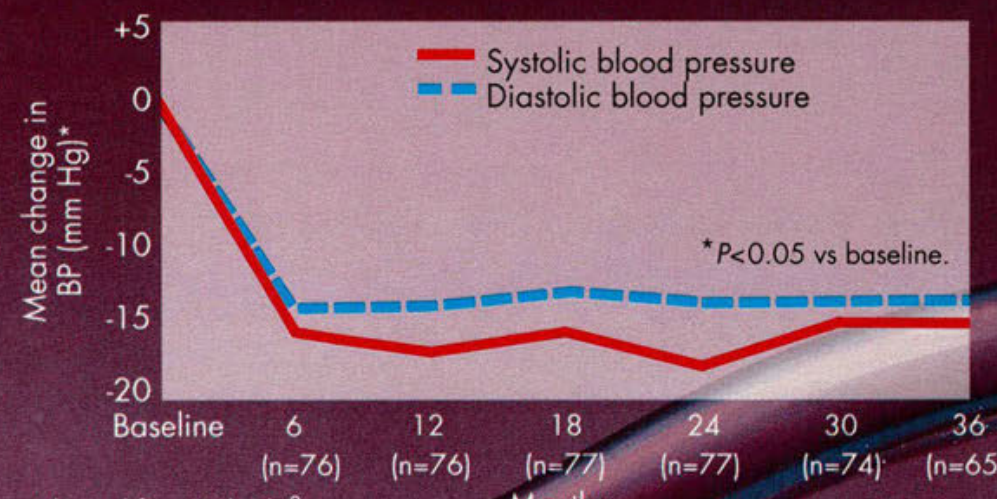

Adapted from Talseth. ${ }^{3}$ Months

NEW, ONCE-A-DAY (doxazosin mesylate) Treats hypertension at its source 


\section{Vasculoactive CARDURA}

CARDURA's discontinuation rate is $2 \%$ - same as placebo

¿2 CARDURA has not been associated with any drug interactions (as measured by protein binding) in in vitro and in vivo studies ${ }^{2}$

¿ CARDURA has minimal effect on glucose metabolism, insulin levels, ${ }^{4}$ renal function, ${ }^{5}$ electrolytes ${ }^{2}$ and important selected parameters ${ }^{2}$

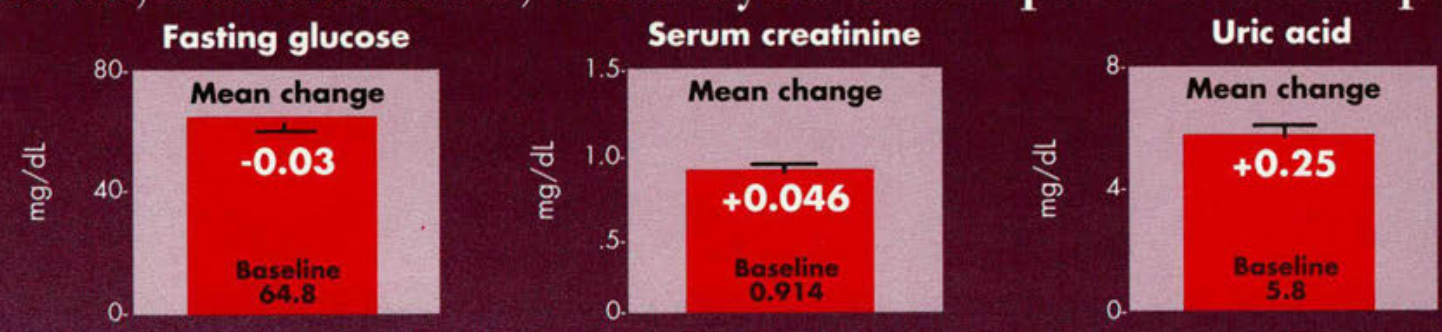

is CARDURA lowers blood pressure without raising cholesterol ${ }^{2}$

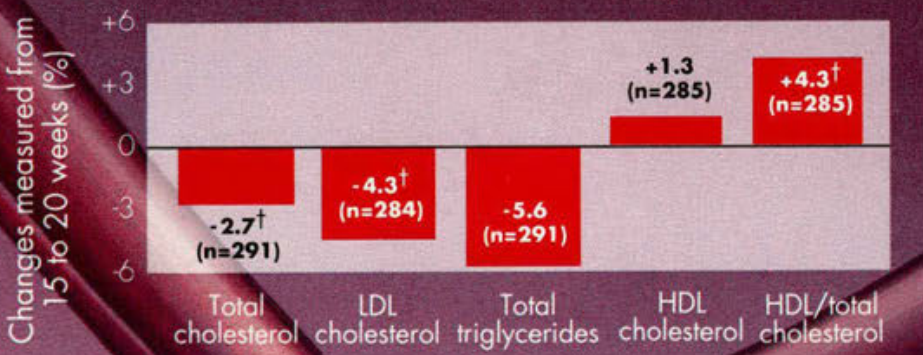

In a pooled analysis of placebo-controlled studies with about 300 patients per treatment group, CARDURA produced small reductions in total and LDL cholesterol, and small increases in the $\mathrm{HDL} /$ total cholesterol ratio. These changes occurred in patients with predominantly normal cholesterol levels. The clinical significance of these findings is uncertain. Cholesterol is just one parameter to consider when selecting the best individ. valized therapy for a given patient.

*The most common side effects that were significant versus placebo were dizziness, somnolence, and fatigue. Syncope has been reported, but rarely $(<1 \%)$.

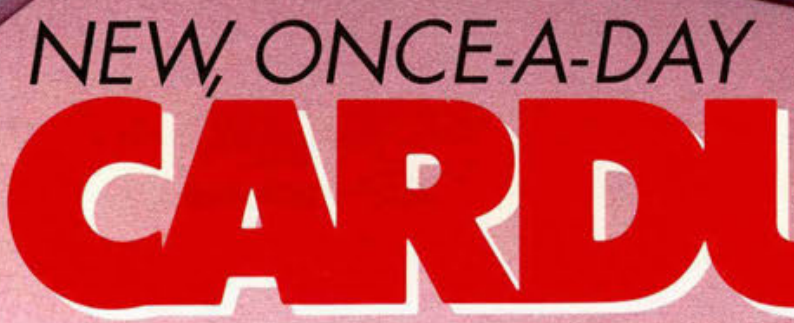

(doxazosin mesylate)

Scored Tablets Treats hypertension at its source 
(doxazosin mesylate) $\begin{aligned} & \text { Scored Tablets } \\ & 1 \mathrm{mg} .2 \mathrm{mg} .4 \mathrm{mg} .8 \mathrm{mg}\end{aligned}$

Convenient once-a-day dosage

Most responsive patients are controlled with one daily dose of 4 to $8 \mathbf{m g}^{2}$

- recommended initial dose is $1 \mathrm{mg}$, with dosage range of $1 \mathrm{mg}$ to $16 \mathrm{mg}$ per day.

References: 1. Weiner N: Drugs that inhibit adrenergic nerves and block adrenergic receptors, in Goodman and Gillman, eds: The Pharmacological Basis of Therapeutics, ed 7. New York, NY, Macmillan Publishing Company. 1985, pp 181-214, 887-907 2 Data available on request from Roerig. 3. Talseth T: Long-term comparison of doxazosin and atenolol in patients with mild or program entitled Management of Coronary Heart Disease Risk Factors in Hypertensive Patients. Clinical Experience with Doxazosin. London. UK, Januar 26. 1990, pp 18-19.4. Scheen AN. Castillo M. Salvatore T, et at Lack of deleterious effects of the alpha,-adrenoreceptor blocking agent doxazosin on insulin secretion and insulin sensitivity in healthy men. Current Therapeutic Research 1989: 46: 200-209.5. Wilner KD. Ziegler MG. Ellects of alpha, inhibition on renal blood flow and sympathetic nervous activity in systemic hypertension. Am J Cardiol 1987.59:826-86C.

CARDURA $^{\otimes}$ (doxazosin mesylate) Tablets Brief Summary of Prescribin CARDURA may be used alone of in combiration with diuretics or beta-adrenerg blocking agents. There is limited experience with CAROURA in combination with CONTRAINDICATIONS

CARDURA is contraindicated in patients with a known sensitivity to quinazolines WARRINGS

Syncope and "First-dose" Effect:

Doxazosin, like other alpha-adrenergic blocking agents, can cause marked hypotension, especially in the upright position, with syncope and other postural symptoms such as dizziness. Marked orthostatic effects are most common with the first dose but can also occur when there is a dosage increase, or if therapy is interrupted for more than a lew days. To decrease the likelihood of excessive hypotension and syncope, it is essential that treatment be initiated with the $1 \mathrm{mg}$ dose. The 2, 4, and $8 \mathrm{mg}$ tablets are not for initial therapy. Dosage should then be adjusted slowly (see DOSAGE AND ADMINISTRATION section
with increases in dose every two weeks. Additional antihypertensive with increases in dose every two weeks.

agents should be added with caution. situations where injury could result should syneope occur.
sitionts being titrated with doxazosin should be cautioned situations where injury could result should syneope occur.
In an early investigational study of the salety and tolerance of increasing daily In an early investigational study of the salety and tolerance of increasing daily
doses of doxazosin in normolensives beginning at 1 mg/day, only 2 of 6 subjects could tolerate more than $2 \mathrm{mg} /$ day without experiencing symptomatic postural hypotension. In another study of 24 healthy normotensive male subjects receiving initial doses of $2 \mathrm{mg} / \mathrm{day}$ of doxazosin, seven $(29 \%)$ of the subjects experienced symptomatic postural hypotension between 0.5 and 6 hours atter the first dose necessitating termination of the study. In this study 2 of the normotensive subjects experienced syncope. Subsequent trials in hypertensive patients always began doxazosin dosing at $1 \mathrm{mg} /$ day resulting in a $4 \%$ incidence of postural side effects a $1 \mathrm{mg} / \mathrm{day}$ with no cases of syncope.

In multiple dose clinical trials involving over 1500 patients with dose titration every one to two weeks, syncope was reported in $0.7 \%$ of patients. None of these 作 If syncope occurs, the patient should be placed in a recumbent position and treated supportively as necessary.

PRECAUTIONS

General:

1. Orthostatic Hypotension:

While syncope is the most severe orthostatic effect of CARDURA, other symptoms of lowered blood pressure, such as diziness, lightheadedness, or vertigo, can

occur, especially at initiation of therapy or at the time of dose increases. These were discontinuation of therapy in about $2 \%$.

In placebo controlled titration trials orthostatic effects were minimized by beginning therapy at $1 \mathrm{mg}$ per day and titrating every two weeks to 2.4 , or $8 \mathrm{mg}$ per day. There was an increased frequency of orthostatic effects in patients given $8 \mathrm{mg}$ or more, $10 \%$, compared to $5 \%$ at $1-4 \mathrm{mg}$ and $3 \%$ in the placebo group. Patients in occupations in which orthostatic hypotension could be dangerous should be treated with particular caution.

It hypotension occurs, the patient should be placed in the supine position and, this measure is inadequate, volume expansion with intravenous fluids of vasopressor therapy may be used. A transient hypotensive response is not a contraindication to turther doses of CAROURA.

2. Impaired liver function:

CARDURA should be administered with caution to patients with evidence impaired hepatic function or to patients receiving drugs known to influence hepatic metabolism (see CLINICAL PHARMACOLOGY) There is no controlled clinical experience with CARDURA in patients with these conditions.

3. Leukopenia/Neutropenia:

Analysis of hematologic data from patients receiving CARDURA in controlled Clinical trials showed that the mean WBC (N-474) and mean neutrophil counts
$(\mathrm{N}=419)$ were decreased by $24 \%$ and $10 \%$ respectively, compared to plasebo, (N-419) were decreased by $2.4 \%$ and $1.0 \%$ respectively, compared to placebo, a 2400 patients revealed 4 in which drug-related neutropenia could not be ruled out. Two had a single low value on the last day of treatment. Two had stable, nonprogressive neutrophil counts in the $1000 / \mathrm{mm}^{3}$ range over periods of 20 and 40 weeks. In cases where foll low-up was available the WBCS and neutrophil cou symptomatic as a result of the low WBC or neutrophil counts. symptomatic as a result of the

Patients should be made aware of the possibility of syncopal and orthostatic symptorns, especially at the initiation of therapy, and urged to avoid driving of hazardous tasks for 24 hours atter the first dose, atter a dosage increase, and after interruption of therapy when treatment is resumed. They should be cautioned to avoid situations where injury could result should syncope occur during initiation of doxazosin therapy. They should also be advised of the need to sit or lie down when symptoms of lowered blood pressure occur, although these symptoms are not always orthostatic, and to be careful when rising from a sitting or lying position. II with CARDURA $1 \mathrm{mg}$ once daily to minimize side effects. Evaluate supine and standing blood pressure. Prescribe CARDURA 2 mg once daily, if necessary.

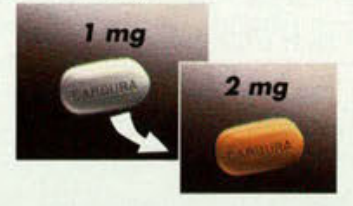

Begin all patients

Evaluate for blood pressure control. Prescribe 4 mg once daily, if necessary.

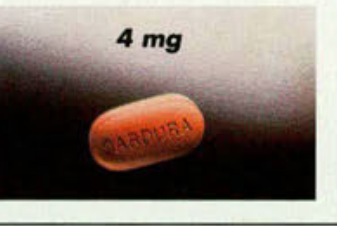

diziness, lightheadedness, or palpitations are bothersome they should be reported to the physician, so that dose adjustment can be considered. Patients should also be told that drowsiness or somnolence can occur with doxarosin, requiring caution in people who must drive or operate heavy machinery.

Drug interactions:

Most $(98 \%)$ of plasma doxazosin is protein bound. In vitro data in human plasma indicate that CARDURA has no eflect on protein binding of digoxin, wartarin, phenytoin of indomethacin. There is no information on the effect of other high plasma protein bound drugs on doxazosin binding. CARDURA has been administered without any evidence of an adverse drug interaction to patien

Drug/Laboratory test interactions:

None known

Cardiac Toxicity in Animals:

An increased incidence of myocardial necrosis or fibrosis was displayed by Sprague-Dawley rats after 6 months of dietary administration at concentrations calculated to provide $80 \mathrm{mg}$ doxazosin/kg/day and atter 12 months of dietary

administration at concentrations calculated to provide $40 \mathrm{mg}$ doxazosin/kg/day

(150 times the maximum recommended human dose assuming a patient weight of $60 \mathrm{~kg}$. There is no evidence that similar lesions occur in humans. Carcinogenesis, Mutagenesis and Impairment of Fertility: Chronic dietary administration (up to 24 months) of doxazosin mesylate at maximally tolerated concentrations (highest dose $40 \mathrm{mg} / \mathrm{kg}$ : about 150 times the maximum recommended human dose of $16 \mathrm{mg} / 60 \mathrm{~kg}$ ) revealed no evidence of carcinogenicity in rats. There was also no evidence of carcinogenicity in a similarly conducted study (up to 18 months of dietary administration) in mice. The mouse
study, however, was compromised by the failure to use a maximally tolerated dose
of doxazosin.

Mulagenicity studies revealed no drug- or metabolite-related effects at either chromosomal or subchromosomal levels

Studies in rats showed reduced fertility in males treated with doxazosin at oral doses of 20 (but not 5 or 10 ) mg/kg/day, about 75 times the maximum

recommended human dose. This effect was reversible within two weeks of drug

Writhdrawal.

Teratogenic Effects, Pregnancy Category B. Studies in rabbits and rats at

Teratogenic Effects, Pregnancy Category B. Studies in raboits and rats at
daily oral doses of up to 40 and $20 \mathrm{mg} / \mathrm{kg}$, respectively (150 and 75 times the

maximum recommended daily dose of $16 \mathrm{mg}$, assuming a patient weight of $60 \mathrm{~kg}$ ).

have revealed no evidence of harm to the fetus. The rabbit study, however, was compromised by the failure to use a maximally tolerated dose of doxazosin. There are no adequate and well-controlled studies in pregnant women. Because anima reproduction studies are not always predictive of human

Radioactivity was tound to cross the plabenta following oral administration of abelled doxarosin to pregn

Nonteratogenic Elfects. In peri-postnatal studies in rats, postnatal development to maternal doses of 40 or $50 \mathrm{mg} / \mathrm{kg} / \mathrm{day}$ of dorarosin was delayed as evidenced by slower body weight gain and a slightly later appearance of anatomical teatures and reflexes.

It is not known whether this drug is excreted in human milk. Because many drugs are excreted in human milk, caution should be exercised when CAROURA is

Pediatric Use

ildren have not been established.

ADVERSE REACTIONS

CARDURA has been administered to approximately 4000 patients, of whom 1679 were included in the clinical development program. In that program, minor adverse effects were frequent, but led to discontinuation of treatment in only $7 \%$ of patients in the doxazosin and placebo groups, respectively, and led to discontinuation in $2 \%$ of patients in each group. The major reasons for discontinuation were postural effects (2\%), edema, malaise/tatigue, and some heart rate disturbance, each about

$0.7 \%$ In controlled clinical trials directly comparing CARDURA to placebo there was no significant difference in the incidence of side etfects, except for dizziness (including postura), weight gain, somnolence and tatigue/malaise. Postural effects and edema appeared to be dose relat

the prevalence rates presented below are based on combined data from placebocontrolled studies involving once dally administration of doxarosin al doses ranging from 1-16 mg. Table 1 summarizes those adverse experiences (possibly/probably related) reported for patients in these studies where the prevalence rate in the doxazosin group was at least $0.5 \%$ or where the reaction is of particular interest.

\begin{tabular}{llcc}
\hline \multicolumn{4}{l}{ TABLE 1: ADVERSE REACTIONS DURING PLACEBO CONTROLLED STUDIES } \\
\hline & & $\begin{array}{c}\text { DOXAZOSIN } \\
(\mathrm{N}-339)\end{array}$ & $\begin{array}{c}\text { PLACEBO } \\
(\mathrm{N}-336)\end{array}$ \\
\hline CARDIOVASCULAR & Diziness & $19 \%$ & $9 \%$ \\
& Vertigo & $2 \%$ & $1 \%$ \\
& Postural Hypotension & $0.3 \%$ & $0 \%$ \\
& Edema & $4 \%$ & $3 \%$ \\
& Palpitation & $2 \%$ & $3 \%$ \\
& Arrtythmia & $1 \%$ & $0 \%$ \\
& Hypotension & $1 \%$ & $0 \%$ \\
& Tachycardia & $0.3 \%$ & $1 \%$ \\
& Peripheral Ischemia & $0.3 \%$ & $0 \%$ \\
\hline SKIN APPENDAGES & Rash & $1 \%$ & $1 \%$ \\
& Pruritus & $1 \%$ & $1 \%$ \\
\hline MUSCULOSKELETAL. & Arthralgia/Arthritis & $1 \%$ & $0 \%$ \\
& Muscle Weakness & $1 \%$ & $0 \%$ \\
& Myalgia & $1 \%$ & $0 \%$ \\
\hline CENTRAL \& & Headache & $14 \%$ & $16 \%$ \\
PERIPHERAL N.S. & Paresthesia & $1 \%$ & $1 \%$
\end{tabular}

7. Evaluate for blood pressure control.

Prescribe $8 \mathrm{mg}$ on daily, if necessary. Maximum recommended dosage is $16 \mathrm{mg}$ once daily.

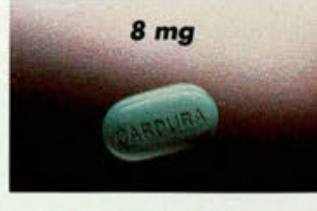

DOXAZOSIN PLACE

\begin{tabular}{|c|c|c|}
\hline & $\begin{array}{l}\text { Kinetic Disorders } \\
\text { Ataxia } \\
\text { Hypertonia } \\
\text { Muscle Cramps }\end{array}$ & $\begin{array}{l}1 \% \\
1 \% \\
1 \% \\
1 \%\end{array}$ \\
\hline AUTONOMIC & $\begin{array}{l}\text { Mouth Dry } \\
\text { Flushing }\end{array}$ & $\begin{array}{l}2 \% \\
1 \%\end{array}$ \\
\hline SPECIAL SENSES & $\begin{array}{l}\text { Vision Abnormal } \\
\text { Conjunctivitis/Eye Pain } \\
\text { Tinnitus }\end{array}$ & $\begin{array}{l}2 \% \\
1 \% \\
1 \%\end{array}$ \\
\hline PSYCHIATRIC & $\begin{array}{l}\text { Somnolence } \\
\text { Nervousness } \\
\text { Depression } \\
\text { Insomnia } \\
\text { Sexual Dystunction }\end{array}$ & $\begin{array}{l}5 \% \\
2 \% \\
1 \% \\
1 \% \\
2 \%\end{array}$ \\
\hline GASTROINTESTINAL & $\begin{array}{l}\text { Nausea } \\
\text { Diarrhea } \\
\text { Constipation } \\
\text { Dyspepsia } \\
\text { Flatulence } \\
\text { Abdominal Pain } \\
\text { Vomiting }\end{array}$ & $\begin{array}{l}3 \% \\
2 \% \\
1 \% \\
1 \% \\
1 \% \\
0 \% \\
0 \%\end{array}$ \\
\hline RESPIRATORY & $\begin{array}{l}\text { Rhinitis } \\
\text { Dyspnea } \\
\text { Epistaxis }\end{array}$ & $\begin{array}{l}3 \% \\
1 \% \\
1 \%\end{array}$ \\
\hline URINARY & $\begin{array}{l}\text { Polyuria } \\
\text { Urinary Incontinence } \\
\text { Micturation Frequency }\end{array}$ & $\begin{array}{l}2 \% \\
1 \% \\
0 \%\end{array}$ \\
\hline GENERAL & $\begin{array}{l}\text { Fatigue/Malaise } \\
\text { Chest Pain } \\
\text { Asthenia } \\
\text { Face Edema } \\
\text { Pain }\end{array}$ & $\begin{array}{r}12 \% \\
2 \% \\
1 \% \\
1 \% \\
2 \%\end{array}$ \\
\hline
\end{tabular}

Additional adverse reactions have been reported, but these are, in general, distinguishable trom symptoms that might have occurred in the absent exposure to doxazosin. The following adverse reactions occurred with a freque between $0.5 \%$ and $1 \%$. syncope, hypoeshesia, increased sweating. agitation, $40.5 \%$ of 3960 patients who received doxazosin in controlled or open, shortlong-term clinical studies, including international studies, Cardiovascular Sys angina pectoris, myocardial intarction, cerebrovascular accident; Autonomic Nervous System pallor, Metabolic thirst, gout, hypokalemia, Hematopoietic Iymphadenopathy, purpura; Reproductive System: breast pain; Skin Disorder alopecia dry skin eczema. Central Nervous System paresis, tremor, twitching contusion, migraine, impaired concentration: Psychiatric paroniria, amnesia emotional lability, abnormal thinking, depersonalization; Special Senses: paro earache, taste perversion, photophobia, abnormal lacrimation; Gastrointestin System: increased appetite, anorexia, tecal incontinence, gastroenteritis; Resp System: bronchospasm, sinusitis, coughing, pharyngitis; Urinary System: ren
calculus; General Body System hot flashes, back pain, intection, tever/rigors, decreased weight influenza-like symptoms.

CARDURA weight, influenza-like symptoms.
CARD not been associated with any clinically significant changes in routine biochemical tests. No clinically relevant adverse effects were noted on serum potassium, serum glucose, uric acid. blood urea nitrogen, creatinine or function tests CARDURA has been associated with decreases in white blood counts (See Precautions).

The oral $L \mathrm{D}_{50}$ of doxazosin is greater than $1000 \mathrm{mg} / \mathrm{kg}$ in mice and rats. The Iikely manifestation of overdosage would be hypotension, for which the usual treatment would be intravenous infusion of fluid. As doxazosin is highly prote bound, dialysis would not be indicated.

DOSAGE MUST BE INDIVIDUALIZED. The initial dosage of CARDURA in hypertensive patients is $1 \mathrm{mg}$ given once daily. Depending on the individual patient's standing blood pressure response (based on measurements taken at hours postdose and 24 hours postdose), dosage may then be increased to $2 \mathrm{~m}$ thereatter if necessary to $4 \mathrm{mg}, 8 \mathrm{mg}$ and $16 \mathrm{mg}$ to achieve the desired reduct blood pressure. Increases in dose beyond $4 \mathrm{mg}$ increase the likelihood of exce postural effects including syncope, postural diziness/vertigo, postural hypoter At a titrated dose of $16 \mathrm{mg}$ once daily the frequency of postural effects is about compared $103 \%$ tor placeoo.

HOW SUPPLIED

CARDURA (doxazosin mesylate) is available as colored tablets for ora administration. Each tablet contains doxazosin mesylate equivalent to $1 \mathrm{mg}$ ( $2 \mathrm{mg}$ (yellow), $4 \mathrm{mg}$ (orange) or $8 \mathrm{mg}$ (green) of the active constituent, doxaz CAROURA TABLETS are available as $1 \mathrm{mg}$ (white), $2 \mathrm{mg}$ (yellow), $4 \mathrm{mg}$ (or (NDC 0049-2760-66), $4 \mathrm{mg}$ (NDC 0049-2770-66). $8 \mathrm{mg}$ (NDC 0049-2780-66 Recommended Storage: Store below $86^{\circ} \mathrm{F}\left(30^{\circ} \mathrm{C}\right)$.

CAUTION: Federal law prohibits dispensing without prescription. $65-4538-00-0$

\section{Tfirer Roerig}

A division of Pfizer Pharmaceuticals 